\title{
Density of intertidal barnacles along their full elevational range of distribution conforms to the abundant-centre hypothesis
}

\author{
Ricardo A Scrosati ${ }^{\text {Corresp., }}{ }^{1}$, Matthew J Freeman ${ }^{1}$ \\ ${ }^{1}$ Department of Biology, St. Francis Xavier University, Antigonish, Nova Scotia, Canada \\ Corresponding Author: Ricardo A Scrosati \\ Email address: rscrosat@stfx.ca
}

The abundant-centre hypothesis ( $\mathrm{ACH}$ ) predicts that the density of a species should peak at its distribution centre and decrease similarly towards distribution margins. The $\mathrm{ACH}$ has been deduced from a theory that postulates that environmental conditions should be most favourable for a species at the centre of its distribution. This idealized density pattern, however, has been supported by limited field studies, as natural patterns are often more complex. It is thus of interest to examine under what conditions compliance with the $\mathrm{ACH}$ could be favoured. Such conditions could be smooth environmental gradients with limited habitat patchiness throughout the distribution range of a species. Thus, we tested the ACH by measuring the density of an intertidal barnacle (Semibalanus balanoides) across its full vertical distribution range (from low to high elevations) on a rocky shore with similar substrate properties across elevations. To do a reliable test, we surveyed eight elevation zones applying an equal sampling effort in each zone. Average barnacle density conformed to the $\mathrm{ACH}$, as it peaked at the middle of the vertical distribution range of this species. The same underlying theory predicts a similar unimodal pattern for maximum body size, but this trait was decoupled from density, as maximum barnacle size increased from low to high elevations. Overall, although the $\mathrm{ACH}$ is not a universal predictive tool as once envisioned, it may predict some cases well, as shown by this study. Therefore, the ACH should not be discarded completely, and its domain of application should be further evaluated. 
1 Density of intertidal barnacles along their full elevational range of distribution conforms to the abundant-centre hypothesis

4 St. Francis Xavier University, Department of Biology, Antigonish, Nova Scotia B2G 2W5,

* Corresponding author. Email: rscrosat@stfx.ca. Phone: 1-902-867-5289 


\section{ABSTRACT}

The abundant-centre hypothesis $(\mathrm{ACH})$ predicts that the density of a species should peak at

10 its distribution centre and decrease similarly towards distribution margins. The ACH has been

11 deduced from a theory that postulates that environmental conditions should be most favourable

12 for a species at the centre of its distribution. This idealized density pattern, however, has been

13 supported by limited field studies, as natural patterns are often more complex. It is thus of

14 interest to examine under what conditions compliance with the ACH could be favoured. Such

15 conditions could be smooth environmental gradients with limited habitat patchiness throughout

16 the distribution range of a species. Thus, we tested the $\mathrm{ACH}$ by measuring the density of an

17 intertidal barnacle (Semibalanus balanoides) across its full vertical distribution range (from low

18 to high elevations) on a rocky shore with similar substrate properties across elevations. To do a

19 reliable test, we surveyed eight elevation zones applying an equal sampling effort in each zone.

20 Average barnacle density conformed to the $\mathrm{ACH}$, as it peaked at the middle of the vertical

21 distribution range of this species. The same underlying theory predicts a similar unimodal pattern

22 for maximum body size, but this trait was decoupled from density, as maximum barnacle size

23 increased from low to high elevations. Overall, although the $\mathrm{ACH}$ is not a universal predictive

24 tool as once envisioned, it may predict some cases well, as shown by this study. Therefore, the

25 ACH should not be discarded completely, and its domain of application should be further

26 evaluated. 
The abundant-centre hypothesis $(\mathrm{ACH})$ predicts that the density of a species should peak at its distribution centre and decrease similarly towards the distribution margins. The $\mathrm{ACH}$ has

31 been deduced from a theory that postulates that environmental conditions should be most

32 33

favourable for a species at its distribution centre (Brown, 1984). These concepts were conceived without particularly considering the extent of species distributions, which can be large or small depending mainly on limits imposed by the physical environment. In addition, distribution ranges can be examined in various directions (e.g., horizontally along forest transects or vertically across mountain elevations). The convenient simplicity of the $\mathrm{ACH}$ has been used to generate more complex hypotheses predicting, for example, changes in population persistence, genetic diversity, speciation potential, and consumer control from the distribution margins of a species to its distribution centre (Lawton et al., 1994; Lesica \& Allendorf, 1995; Channell \& Lomolino, 2000; Holt \& Keitt, 2000; Eckert, Samis \& Lougheed, 2008; Dixon, Herlihy \& Busch, 2013; Micheletti \& Storfer, 2015). However, field tests of the ACH have produced mixed results. While some surveys have supported the $\mathrm{ACH}$, others have failed to do so, finding various levels of departure from the idealized unimodal trend for density (Sagarin \& Gaines, 2002; Rivadeneira et al., 2010; Tam \& Scrosati, 2011; Pironon et al., 2017; Dallas, Decker \& Hastings, 2017). Such departures often result, in part, from the patchiness that abiotic conditions generally display across space in the real world (Helmuth et al., 2002; Gilman, 2005; Tam \& Scrosati, 2011; Martínez-Meyer et al., 2013).

While the $\mathrm{ACH}$ is not a universal predictive tool as once envisioned, it could retain some usefulness in certain cases. One such case might be species distribution ranges that span smooth environmental gradients. In rocky intertidal habitats, for example, there is a strong change in 
51 abiotic conditions from low to high elevations because of tides (Raffaelli \& Hawkins, 1999;

52 Menge \& Branch, 2001). While low elevations remain submerged most of the time, high

53 elevations are frequently exposed to the air. Thus, for exclusively intertidal species, which are

54 adapted to some degree of aerial exposure, the upper and lower margins of the intertidal range

55 represent environmental extremes. Therefore, unless substrate properties are too patchy across

56 elevations, sessile species that are only intertidal and span the full intertidal range could

57 experience the most favourable conditions at middle elevations. This line of reasoning suggests

58 that the $\mathrm{ACH}$ could hold for such species. On Atlantic Canadian rocky shores, the barnacle

59 Semibalanus balanoides is an exclusively intertidal sessile species whose vertical distribution

60 range spans low to high elevations (Scrosati \& Heaven, 2008). Thus, under the above

61 considerations, it is a suitable species for $\mathrm{ACH}$ testing.

62 Field tests of the ACH are most reliable when surveys cover the full distribution range of a

63 species and apply the same sampling effort across the range (Gaston, 2003). However, due to

64 factors that limit site access (e.g., rough topography or poor roads), these two key requirements

65 have not always been met (Dallas, Decker \& Hastings, 2017). Such difficulties generally do not

66 apply to intertidal studies, as the full vertical distribution of intertidal species can be surveyed

67 easily during low tides taking data at several elevation zones. Thus, some studies counted

68 intertidal organisms across several elevation zones (Bell, 1979; Brown, 1984), but replication

69 was either poor or not reported and statistical analyses not done. In 2011, a well-replicated study

70 tested the $\mathrm{ACH}$ for Semibalanus balanoides using density data for eight elevation zones

71 spanning the full vertical distribution range of this species. Although statistical analysis revealed

72 a unimodal density trend across elevations, density peaked at a higher elevation than expected,

73 thus providing weak support for the ACH (Scrosati, Grant \& Brewster, 2012). In ecology, 
74 equally important as replication of sampling units is the replication of whole studies. Repeating

75 studies in the future allows for the determination of pattern consistency, which is essential in the

76 process of developing and refining theories (Krebs, 1999; Ford, 2000). Therefore, seven years

77 after the study that tested the ACH using Semibalanus balanoides density data (Scrosati, Grant

$78 \&$ Brewster, 2012), we replicated the survey with the objective of evaluating the temporal

79 consistency of the pattern.

80 Body size is an important emergent property of organisms (Lika, Augustine \& Kooijman,

81 2019). It is related to ecological performance (Brown et al., 2004) and affects upper trophic

82 levels through consumptive interactions (Dunkin \& Hughes, 1984; Carroll \& Wethey, 1990). The

83 theory from which the ACH has been deduced (conditions should be best for a species at its

84 distribution centre; Brown, 1984) can also be employed to predict spatial trends in maximum

85 body size. Specifically, maximum body size can be predicted to peak at the distribution centre of

86 a species and decrease towards its distribution margins (Scrosati, Grant \& Brewster, 2012).

87 Some studies have measured how the body size of invertebrates changes along vertical intertidal

88 gradients (Vermeij, 1972; Bertness, 1977; McCormack, 1982; McQuaid, 1982; Hobday, 1995),

89 but those studies only considered mobile invertebrates. Data measured at a single point in time

90 describing body size of mobile species across intertidal elevations may be highly influenced by

91 recent abiotic conditions, as mobile species move up and down the shore when conditions

92 change (e.g., hot versus cool days). In contrast, body size data for sessile species (such as

93 barnacles) integrate much better the environmental influences over the long term. The study done

94 in 2011 on Semibalanus balanoides also tested the above prediction for maximum body size and

95 found that this trait varied unimodally across elevations but, like density, peaking at a higher 
96 elevation than expected (Scrosati, Grant \& Brewster, 2012). Therefore, the present study

97 replicates that study also with the goal of evaluating pattern consistency.

We did this study at Tor Bay Provincial Park $\left(45^{\circ} 11^{\prime} \mathrm{N}, 61^{\circ} 21^{\prime} \mathrm{W}\right)$, on the Atlantic coast of Nova Scotia, Canada, on 25 November 2018. We surveyed wave-sheltered intertidal habitats, which are protected from direct oceanic swell by outer islets and are characterized by values of daily maximum water velocity of 3-6 $\mathrm{m} \mathrm{s}^{-1}$ (Scrosati \& Heaven, 2007). The surveyed habitats are composed of stable bedrock with a similar rugosity and a steep slope from low to high elevations. On this coast, Semibalanus balanoides (Fig. 1) is the only intertidal barnacle species (Scrosati \& Heaven, 2007). Organisms of this species can live for a few years (Anderson, 1994). The vertical intertidal range is $1.8 \mathrm{~m}$ on this coast. To test our hypotheses, we surveyed intertidal habitats spanning several metres along the coastline. In these habitats, we first used tide tables to divide the intertidal range into nine elevation zones of equal vertical extent $(0.2 \mathrm{~m})$. As barnacles were absent at the lowest zone (between $0-0.2 \mathrm{~m}$ of elevation), the full vertical distribution range

110 of this barnacle was deemed to span $1.6 \mathrm{~m}$ (the eight zones between $0.2-1.8 \mathrm{~m}$ of elevation,

111 relative to chart datum). For each of those zones, we determined the density and maximum body

112 size of Semibalanus balanoides for 10 quadrats $(20 \mathrm{~cm}$ x $20 \mathrm{~cm})$ randomly established following

113 the coastline. We calculated density as the number of barnacles found in a quadrat divided by

114 quadrat area $\left(4 \mathrm{dm}^{2}\right)$. We measured maximum body size as the basal diameter (to the nearest 1

$115 \mathrm{~mm}$ ) of the widest barnacle found in a quadrat using a ruler.

116 We determined how barnacle density and maximum body size changed across elevations by

117 calculating a generalized additive model (GAM) with a Gamma distribution (Zuur et al., 2009)

118 for each of these two barnacle traits, elevation zone being the independent variable in both 
119 models. A GAM identifies the most suitable functional relationship without any pre-set shape in

120 mind. For both cases, the basis dimension (k) for the smoother was 5 and predictor-vs-residuals

121 plots did not show any evident structure. To evaluate the level of support for each GAM, we

122 compared its AICc value (corrected Akaike Information Criterion) with the AICc value of the

123 corresponding intercept-only model (the model for the same barnacle trait including an intercept

124 but not elevation zone). A GAM was deemed to have substantial support if its AICc score was

125 lower than the AICc score of the intercept-only model by more than 6 units of difference

126 (Harrison et al., 2018). For each barnacle trait, we calculated the evidence ratio to determine

127 specifically how many times more plausible the GAM was relative to the intercept-only model

128 (Anderson, 2008). Finally, for each GAM, we determined the percentage of variation in either

129 density or maximum body size explained by elevation by calculating the explained deviance

130 (Zuur et al., 2009). We conducted these analyses with R version 3.5.1 (R Core Team, 2018),

131 using the mgcv package to calculate the four models and the MuMIn package to calculate the

132 corresponding AICc scores. The full data set used for this paper is available from the figshare

133 online repository (Scrosati \& Freeman, 2019).

$134 \quad$ RESULTS

135 The density of Semibalanus balanoides followed a unimodal trend across the vertical

136 distribution range of this species, peaking at the centre of this range (Fig. 2). The GAM

137 describing this relationship had an AICc score of 458.8, more than 6 units lower than the AICc

138 score of 472.2 for the intercept-only model. Based on the evidence ratio, the GAM was 816

139 times more plausible than the intercept-only model. The estimated degrees of freedom for the

140 GAM were 2.5. The percentage of variation in barnacle density explained by intertidal elevation

141 (explained deviance) was $16 \%$. 
142 The maximum body size of Semibalanus balanoides increased relatively consistently from

143 the lower distribution margin of this species to its upper distribution margin (Fig. 2). The GAM

144 describing this trend had an AICc score of 339.8, more than 6 units lower than the AICc score of

145359.2 for the intercept-only model. Based on the evidence ratio, the GAM was 16,564 times

146 more plausible than the intercept-only model. The estimated degrees of freedom for the GAM

147 were 1.4. The percentage of variation in maximum body size explained by intertidal elevation 148 was $27 \%$.

DISCUSSION

The 2018 data on Semibalanus balanoides supported the ACH. Density exhibited a

151 unimodal pattern across the full vertical distribution range of this species and peaked at the

152 middle of the range. Intertidal elevation explained only a moderate amount of the observed

153 variation in density, but the overall trend predicted by the $\mathrm{ACH}$ was nonetheless highly

154 supported, based on the evidence ratio. The 2011 study, done on the same coast with the same

155 field methodology, had also found a unimodal pattern for Semibalanus balanoides density across

156 elevations, but density then peaked at a higher elevation than predicted by the ACH (Scrosati,

157 Grant \& Brewster, 2012). Thus, while both studies suggest that a unimodal vertical distribution

158 pattern is common for this species, density may or may not peak where the ACH predicts.

159 Nonetheless, the 2018 study reveals that the idealized abundant-centre distribution can indeed

160 occur. Therefore, although now known not to be a universally valid concept, the ACH does

161 retain some usefulness. This example is thus a valuable addition to the limited number of studies

162 that have supported the ACH through surveys on a variety of species (Sagarin \& Gaines, 2002;

163 Tuya, Wernberg \& Thomsen, 2008; Rivadeneira et al., 2010; Pironon et al., 2017). 
164 Explaining what factors modified (2011 vs. 2018) the elevation with the highest density of

165 Semibalanus balanoides is difficult given the absence of experimental data for the studied coast.

166 Future efforts aiming to explain interannual differences could examine interannual changes in

167 abiotic factors (Jones, Southward \& Wethey, 2012), positive and negative effects of algal

168 canopies (Beermann et al., 2013), and consumptive (Menge, 1976) and nonconsumptive (Ellrich,

169 Scrosati \& Molis, 2015) effects of predators. Although barnacles compete with mussels on other

170 rocky shores (Lubchenco and Menge, 1978; Peterson, 1979), mussels are almost absent in the

171 studied sheltered habitats (Scrosati \& Heaven, 2007).

172 The 2018 data on the maximum body size of Semibalanus balanoides failed to support the

173 hypothesized trend deduced from the theory that also underlies the ACH. In 2011, maximum

174 body size had followed (like density) a unimodal pattern across elevations, peaking at a higher

175 elevation than the distribution centre (Scrosati, Grant \& Brewster, 2012). However, in 2018,

176 maximum body size increased relatively smoothly from low to high elevations. Thus, these two

177 studies suggest that, for barnacles, elevational patterns in maximum body size are less stable over

178 the years than those of density. Patterns in maximum body size may (2011) or may not (2018) be

179 coupled to density patterns. For Semibalanus balanoides, no density-dependence should have

180 influenced the relationship between density and maximum body size across elevations, because

181 crowding did not occur on the studied shore in any of the two studied years (Fig. 1; Scrosati,

182 Grant \& Brewster, 2012). Among invertebrates, there are other examples for which body size

183 increases relatively consistently towards one of the distribution margins (Rivadeneira et al., 184 2010). 
186 Overall, our research with Semibalanus balanoides emphasizes the notion that, while the

$187 \mathrm{ACH}$ is an oversimplistic concept that cannot predict all species distributions, it can predict some

188 cases relatively well. Thus, the ACH should not be discarded completely, and its domain of

189 application should be further evaluated.

$190 \quad$ ACKNOWLEDGEMENTS

191 We thank two anonymous reviewers, Donald Kramer, Derrick Lee, and Martin Lavoie for

192 their constructive comments on an earlier version of this paper.

193 REFERENCES

194 Anderson DT. 1994. Barnacles. Structure, function, development, and evolution. London:

195 Chapman \& Hall.

196 Anderson DR. 2008. Model-based inference in the life sciences: a primer on evidence. New

197 York: Springer.

198 Beermann AJ, Ellrich JA, Molis M, Scrosati RA. 2013. Effects of seaweed canopies and

199 adult barnacles on barnacle recruitment: the interplay of positive and negative influences.

200 Journal of Experimental Marine Biology and Ecology 448:162-170

201 Bell PD. 1979. Some factors affecting distribution and related morphology variations in

202 Balanus balanoides (L.) (Cirripedia, Thoracica). Hydrobiologia 64:179-182

203 Bertness MD. 1977. Behavioral and ecological aspects of shore-level size gradients in Thais

204 lamellosa and Thais emarginata. Ecology 58:86-97

205 Brown JH. 1984. On the relationship between abundance and distribution of species. The

206 American Naturalist 124:255-279 
207 Brown JH, Gilloly JF, Allen AP, Savage VM, West GB. 2004. Toward a metabolic theory

208 of ecology. Ecology 85:1771-1789

209 Carroll ML, Wethey DS. 1990. Predator foraging behavior: effect of a novel prey species on

210 prey selection by a marine intertidal gastropod. Journal of Experimental Marine Biology and

211 Ecology 139:101-117

212 Channell R, Lomolino MV. 2000. Trajectories to extinction: spatial dynamics of the contraction

213 of geographical ranges. Journal of Biogeography 27:169-179

214 Dallas T, Decker RR, Hastings A. 2017. Species are not most abundant in the centre of their

215 geographic range or climatic niche. Ecology Letters 20:1526-1533

216 Dixon AL, Herlihy CR, Busch JW. 2013. Demographic and population-genetic tests provide

217 mixed support for the abundant centre hypothesis in the endemic plant Leavenworthia stylosa.

218 Molecular Ecology 22:1777-1791

219 Dunkin SDB, Hughes RN. 1984. Behavioural components of prey-selection by dogwhelks,

220 Nucella lapillus (L.), feeding on barnacles, Semibalanus balanoides (L.), in the laboratory.

221 Journal of Experimental Marine Biology and Ecology 79:91-103

222 Eckert CG, Samis KE, Lougheed SC. 2008. Genetic variation across species' geographical

223 ranges: the central-marginal hypothesis and beyond. Molecular Ecology 17:1170-1188

224 Ellrich JA, Scrosati RA, Molis M. 2015. Predator nonconsumptive effects on prey recruitment

225 weaken with recruit density. Ecology 96:611-616

226 Ford ED. 2000. Scientific method for ecological research. Cambridge: Cambridge University

227 Press. 
228 Gaston KJ. 2003. The structure and dynamics of geographic ranges. Oxford: Oxford University

229 Press.

230 Gilman S. 2005. A test of Brown's principle in the intertidal limpet Collisella scabra (Gould,

231 1846). Journal of Biogeography 32:1583-1589

232 Harrison XA, Donaldson L, Correa-Cano ME, Evans J, Fisher DN, Goodwin CED,

233 Robinson BS, Hodgson DJ, Inger R. 2018. A brief introduction to mixed effects modelling

234 and multi-model inference in ecology. PeerJ 6:e4794

235

236

237

238

239

240

241

242

243

244

245

246

247

\section{Helmuth B, Harley CDG, Halpin PM, O'Donnell M, Hofmann GE, Blanchette CA. 2002.}

Climate change and latitudinal patterns of intertidal thermal stress. Science 298:1015-1017

Hobday A. 1995. Body-size variation exhibited by an intertidal limpet: influence of wave exposure, tidal height, and migratory behavior. Journal of Experimental Marine Biology and Ecology 189:29-45

Holt RD, Keitt TH. 2000. Alternative causes for range limits: a metapopulation perspective. Ecology Letters 3:41-47

Jones SJ, Southward AJ, Wethey DS. 2012. Climate change and historical biogeography of the barnacle Semibalanus balanoides. Global Ecology and Biogeography 21:716-724

Krebs CJ. 1999. Ecological methodology. Menlo Park: Benjamin Cummings.

Lawton JH, Nee S, Letcher AJ, Harvey PH. 1994. Animal distributions: patterns and process. In: Edwards PJ, May RM, Webb NR, eds. Large-scale ecology and conservation biology. London: Blackwell, 41-58.

Lesica P, Allendorf LW. 1995. When are peripheral populations valuable for conservation? Conservation Biology 9:753-760 
250 Lika K, Augustine S, Kooijman SALM. 2019. Body size as emergent property of metabolism.

251 Journal of Sea Research 143:8-17

252 Lubchenco J, Menge BA. 1978. Community development and persistence in a low rocky

253 intertidal zone. Ecological Monographs 59:67-94

Martínez-Meyer E, Díaz-Porras D, Townsend Peterson A, Yáñez-Arenas C. 2013.

255

Ecological niche structure and rangewide abundance patterns of species. Biology Letters

256

9:20120637

McCormack SMD. 1982. The maintenance of shore-level size gradients in an intertidal snail (Littorina sitkana). Oecologia 54:177-183

McQuaid CD. 1982. The influence of desiccation and predation on vertical size gradients in populations of the gastropod Oxystele variegata (Anton) on an exposed rocky shore. Oecologia 53:123-127

Menge BA. 1976. Organization of the New England rocky intertidal community: role of predation, competition, and environmental heterogeneity. Ecological Monographs 46:355-393

Menge BA, Branch G. 2001. Rocky intertidal communities. In: Bertness MD, Gaines SD, Hay ME, eds. Marine community ecology. Sunderland: Sinauer, 221-251.

Micheletti SJ, Storfer A. 2015. A test of the central-marginal hypothesis using population

267 genetics and ecological niche modelling in an endemic salamander (Ambystoma barbouri).

268 Molecular Ecology 24:967-979

Peterson CH. 1979. The importance of predation and competition in organizing the intertidal

270 epifaunal communities of Barnegat Inlet, New Jersey. Oecologia 39:1-24 
271 Pironon S, Papuga G, Villellas J, Angert AL, García MB, Thompson JD. 2017. Geographic

272 variation in genetic and demographic performance: new insights from an old biogeographical

273 paradigm. Biological Reviews 92:1877-1909

274 Raffaelli D, Hawkins S. 1999. Intertidal ecology. Dordrecht: Kluwer.

275 R Core Team. 2018. $R$ : a language and environment for statistical computing. Vienna: $\mathrm{R}$

276 Foundation for Statistical Computing.

277 Rivadeneira MM, Hernáez P, Baeza JA, Boltaña S, Cifuentes M, Correa C, Cuevas A, del

278 Valle E, Hinojosa I, Ulrich N, Valdivia N, Vásquez N, Zander A, Thiel M. 2010. Testing

279 the abundant-centre hypothesis using intertidal porcelain crabs along the Chilean coast: linking

280 abundance and life-history variation. Journal of Biogeography 37:486-498

281 Sagarin RD, Gaines SD. 2002. Geographical abundance distributions of coastal invertebrates:

282 using one-dimensional ranges to test biogeographic hypotheses. Journal of Biogeography

$283 \quad 29: 985-997$

284 Scrosati RA, Freeman MJ. 2019. Data on barnacle density and maximum body size from Nova

285 Scotia (2018). figshare data set. https://doi.org/10.6084/m9.figshare.7547825.v1

286 Scrosati RA, Grant JL, Brewster JD. 2012. Density and size gradients across species

287 distribution ranges: testing predictions from the abundant-centre model using the vertical

288 distribution of intertidal barnacles. Vie et Milieu 62:197-202

289 Scrosati R, Heaven C. 2007. Spatial trends in community richness, diversity, and evenness

290 across rocky intertidal environmental stress gradients in eastern Canada. Marine Ecology

291 Progress Series 342:1-14 
292 Scrosati R, Heaven C. 2008. Trends in abundance of rocky intertidal seaweeds and filter feeders

293 across gradients of elevation, wave exposure, and ice scour in eastern Canada. Hydrobiologia

$294 \quad 603: 1-14$

295 Tam JC, Scrosati RA. 2011. Mussel and dogwhelk distribution along the north-west Atlantic

296 coast: testing predictions derived from the abundant-centre model. Journal of Biogeography

$297 \quad 38: 1536-1545$

298 Tuya F, Wernberg T, Thomsen MS. 2008. Testing the 'abundant centre' hypothesis on endemic

299 reef fishes in south-western Australia. Marine Ecology Progress Series 372:225-230

300 Vermeij GJ. 1972. Intraspecific shore-level size gradients in intertidal molluscs. Ecology

$301 \quad 53: 693-700$

302 Zuur A, Ieno EN, Walker N, Saveliev AA, Smith GM. 2009. Mixed effects models and

303 extensions in ecology with $R$. New York: Springer. 
306 Fig. 1. Intertidal barnacles (Semibalanus balanoides) from the studied coast. Scale bar: $10 \mathrm{~cm}$.

307 Photograph taken at low tide by R. A. Scrosati on 25 November 2018.

308 Fig. 2. (A) Density and (B) maximum body size (maximum basal diameter) of barnacles

309 (Semibalanus balanoides) at the eight intertidal elevation zones (zone 1 being the lowest) that

310 span the full vertical distribution range of this species. In each graph, the solid line is the GAM

311 depicting the functional relationship and the shaded area indicates the $95 \%$ confidence band. 


\section{Figure 1}

Intertidal barnacles (Semibalanus balanoides) from the studied coast

Intertidal barnacles (Semibalanus balanoides) from the studied coast. Scale bar: $10 \mathrm{~cm}$.

Photograph taken by R. A. Scrosati.

*Note: Auto Gamma Correction was used for the image. This only affects the reviewing manuscript. See original source image if needed for review.

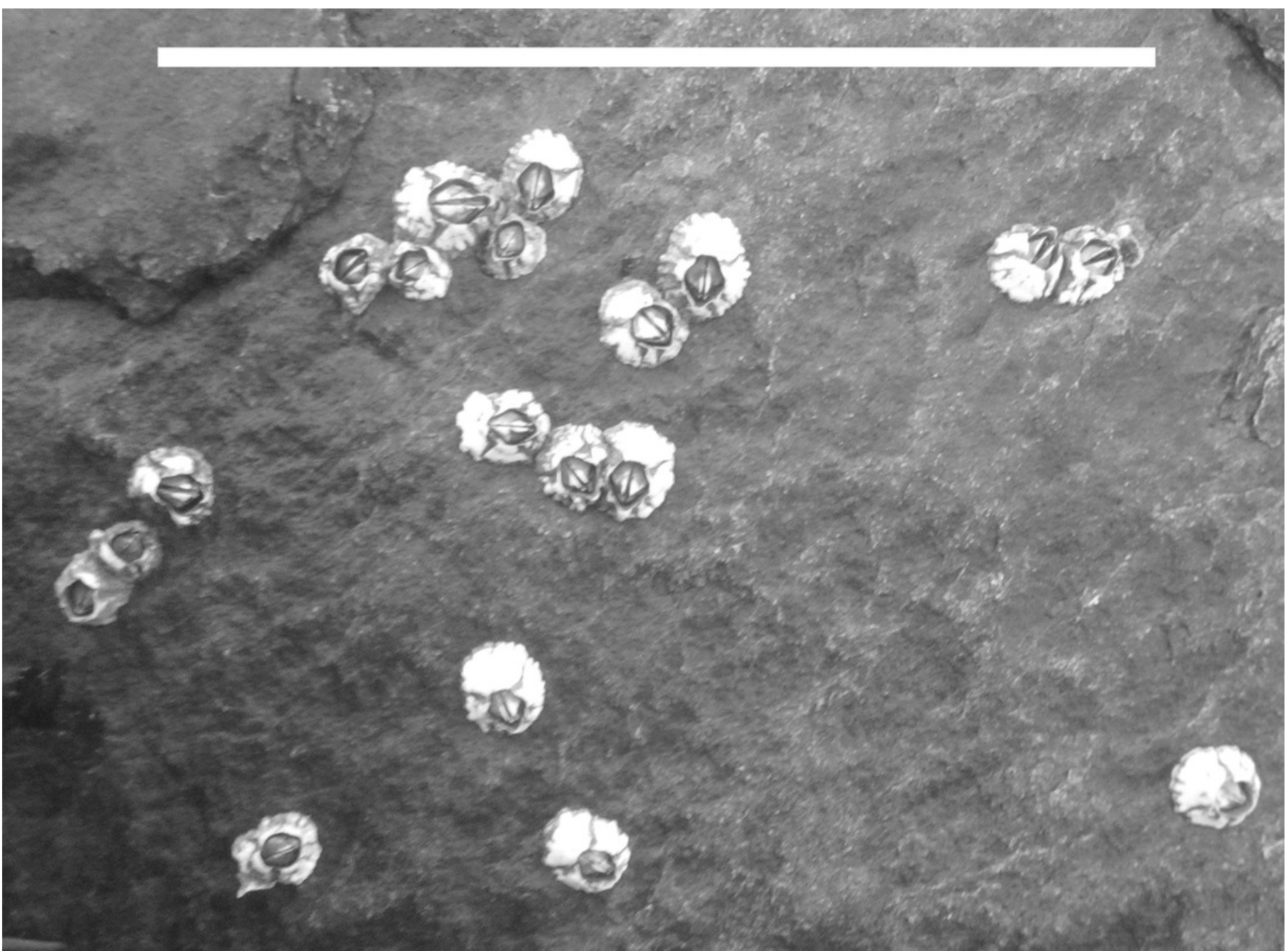


Figure 2

Barnacle density and maximum body size

(A) Density and (B) maximum body size (maximum basal diameter) of barnacles

(Semibalanus balanoides) at the eight intertidal elevation zones (zone 1 being the lowest)

that span the full vertical distribution range of this species. In each graph, the solid line is the GAM depicting the functional relationship and the shaded area indicates the $95 \%$ confidence band.

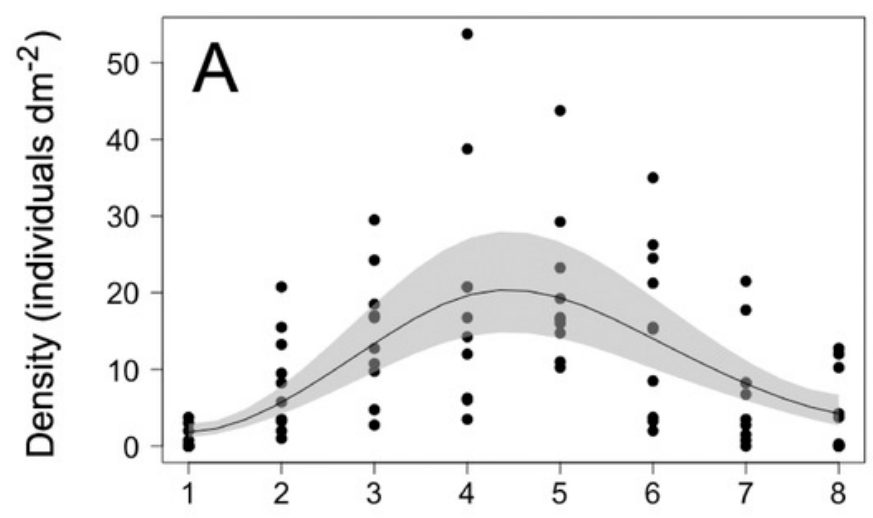

Elevation zone

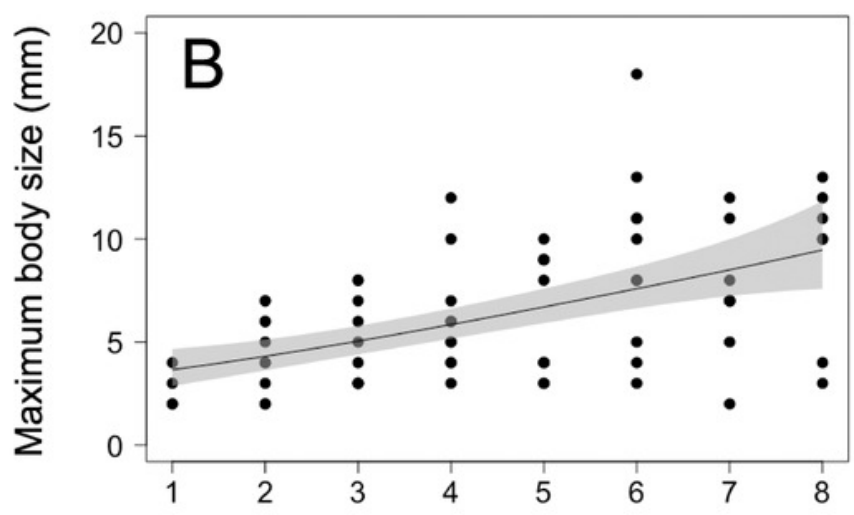

Elevation zone 